\title{
“PROJETO MIGRANTES EGRESSAS”: UMA EXPERIÊNCIA DE TRABALHO DE ORGANIZAÇÃO DA SOCIEDADE CIVIL COM MULHERES MIGRANTES EM CONFLITO COM A LEI NA CIDADE DE SÃO PAULO
}

\author{
"FORMERLY INCARCERATED MIGRANT WOMEN'S PROJECT": A CIVIL SOCIETY \\ ORGANIZATION WORK EXPERIENCE WITH MIGRANT WOMEN IN CONFLICT WITH THE LAW \\ IN THE CITY OF SÃO PAULO
}

Viviane Balbuglio

Mestranda em Direito e Desenvolvimento - Fundação Getúlio Vargas Direito Advogada, atuou por 2 anos como assistente e coordenadora do Projeto Migrantes Egressas Instituto Terra, Trabalho e Cidadania (ITTC)

viviane.balbuglio@gmail.com

Isabela Rocha Tsuji Cunha

Mestre em Direitos Humanos - Universidade de São Paulo, USP Advogada, atuou por 8 anos como assistente e coordenadora do Projeto Estrangeiras (Instituto Terra, Trabalho e Cidadania, ITTC)

isartc@gmail.com

\section{RESUMO}

O presente artigo tem o objetivo de apresentar a experiência de trabalho do Projeto Migrantes Egressas (PME) do Instituto Terra, Trabalho e Cidadania (ITTC), que tem como escopo o atendimento direto com mulheres migrantes egressas do sistema prisional paulista. Propóe-se assim relacionar a experiência de trabalho do projeto junto às mulheres migrantes envolvidas com o sistema penal brasileiro com as mudanças proporcionadas pela nova Lei de Migraçóes (Lei 13.445/2017), além de discutir o acesso a direitos, serviços e políticas públicas no novo cenário que se conforma com cada vez mais mulheres migrantes respondendo processos criminais e cumprindo penas fora do sistema prisional. Se por um lado as medidas tomadas para o desencarceramento de mulheres migrantes representam uma inegável conquista, por outro, a saída da prisão não necessariamente representa o pleno acesso à liberdade, trazendo uma série de novas questóes a serem enfrentadas no cotidiano.

Palavras-chave: Migração. Prisão. Gênero. Liberdade. 


\begin{abstract}
This article aims to present the work experience of Formerly Incarcerated Migrant Women's Project, of the Land, Work and Citizenship Institute (ITTC), which is focused on the direct assistance to migrant women who left the penitentiary system in São Paulo. The proposal is relating the Project's work experience with migrant women who were involved with the brazilian penal system with the changes provided by the new brazilian Migration Law (Law 13.445/2017), in addition to the discussion about access to rights and public services and policies in the new set that comes with more migrant women responding to criminal prosecutions and serving sentences outside the prisons. If on the one hand the measures taken in order to avoid the incarceration of migrant women represent an undeniable achievement, on the other hand, the release of the prison does not necessarily represent full access to freedom, bringing a series of new issues to be faced in everyday life.
\end{abstract}

Key-words: Migration. Prison. Gender. Freedom.

Dara de submissão: 10/12/2018

Data de aceitação: 15/07/2019

\title{
SUMÁRIO
}

INTRODUÇÃO 1. BREVE PANORAMA DO ENCARCERAMENTO DE MULHERES MIGRÁNTES NA CIDADE DE SÃO PAULO. 2. O IMPACTO DA LEI DE MIGRAÇÃO (LEI 13.445/2017) NO ACESSO A DIREITOS POR MULHERES MIGRANTES EM CONFLITO COM A LEI. 3. O INÍCIO DO PROJETO MIGRANTES EGRESSAS (PME), METODOLOGIA E DADOS GERAIS DE ATENDIMENTO. 4. REFLEXÓES SOBRE INTERSECÇÓES ENTRE A JUSTIÇA CRIMINAL E O ACESSO A DIREITOS BÁSICOS A MUSLHERES MIGRANTES EM CONFLITO COM A LEI. CONSIDERAÇÓES FINAIS 


\section{INTRODUÇÁO}

Propóe-se, neste texto, apresentar e proporcionar reflexóes a respeito da experiência do Projeto Migrantes Egressas (PME) do Instituto Terra, Trabalho e Cidadania (ITTC), no que concerne ao trabalho direto com mulheres migrantes em conflitos com a lei.

O Instituto Terra, Trabalho e Cidadania ${ }^{1}$ é uma organização não governamental sediada na cidade de São Paulo/SP, constituída em outubro de 1997, cuja visão é erradicar a desigualdade de gênero, garantir direitos e combater o encarceramento. Ao longo dos seus vinte anos de atuaçáo, o ITTC se tornou uma referência na abordagem e análise das temáticas da justiça criminal e do encarceramento feminino, em especial de mulheres migrantes.

A missão do ITTC é promover o acesso à justiça, garantir os direitos das pessoas presas e produzir conhecimento, por meio de atuação constante e sistemática nos seguintes eixos de ação: atendimento direto, diálogo público e educação para a cidadania. Para alcançar esses objetivos, o Instituto desenvolveu ao longo dos anos um trabalho de proposição de demandas e de mediação de diálogos iniciado pelo Projeto Estrangeiras.

O Projeto Estrangeiras é um projeto permanente do Instituto Terra, Trabalho e Cidadania que, desde 2001, busca atender à missão de acompanhar mulheres migrantes envolvidas com o sistema de justiça criminal. O projeto está pautado em um Protocolo de Intençôes firmado entre o Instituto e a Secretaria da Administraçáo Penitenciária do Estado de São Paulo ${ }^{2}$, o qual tem o intuito de assistir mulheres migrantes privadas de liberdade, de modo a facilitar seu contato com suas famílias e com suas representaçốes diplomáticas, principalmente fornecendo orientação jurídica que permita ampliar o seu acesso à justiça. Desde 2014, este trabalho é realizado em convênio com o Grupo de Trabalho sobre Presas e Presos Estrangeiros da Defensoria Pública da União (DPU) em São Paulo, que partilha estagiárias com o projeto e participa ativamente dos atendimentos diretos e do acompanhamento dos casos $^{3}$.

\footnotetext{
1 A atuaçáo do Instituto como um todo pode ser consultada por meio de seu site e por meio da leitura de sua linha do tempo, a qual foi elaborada em razáo dos 20 anos de atuaçáo do instituto no ano de 2017: <http://ittc.org.br/>. Recomenda-se também a leitura do texto disponível em: <http://ittc.org.br/20-anos-de-luta-pelo-acesso-direitos-das-mulheres-migrantes-presas-em-sao-paulo/>.

2 INSTITUTO TERRA, TRABALHO E CIDADANIA. De estrangeiras a migrantes: os 15 anos de luta do Projeto Estrangeiras. São Paulo: 2016, p.13.

3 INSTITUTO TERRA, TRABALHO E CIDADANIA. De estrangeiras a migrantes: os 15 anos de luta do Projeto Estrangeiras. São Paulo: 2016, p. 30. A parceria entre o ITTC e a DPU é anterior ao ano de 2014, mas foi oficializada com o referido convênio. Ressalta-se que além do acompanhamento semanal de defensores e defensoras públicas aos atendimentos a mulheres migrantes presas em São Paulo, outras iniciativas dentro dessa parceria valem ser mencionadas como: o mutiráo de atendimento médico realizado no Pavilhão Materno-Infantil da Penitenciária Feminina da Capital (PFC) no ano de 2015 e o mutiráo de atendimento a presas migrantes na mesma penitenciária realizado conjuntamente com a Defensoria Pública do Estado de São Paulo (DPESP) também no ano de 2015.
} 
O Projeto Migrantes Egressas (PME), foco deste artigo, deu início às suas atividades em março de $2017^{4} \mathrm{e}$ tem como escopo o trabalho direto com mulheres migrantes egressas do sistema prisional, assim como o mapeamento de redes e realização de diálogo público a partir do acompanhamento realizado com essas mulheres. Com o PME, o ITTC passou a organizar tanto o atendimento direto quanto as atividades de articulação e construçóes de redes voltadas às demandas e vivências das mulheres migrantes egressas junto ao município.

Denomina-se como mulheres migrantes egressas do sistema prisional as mulheres náo brasileiras que possuem antecedentes penais no Brasil. De maneira geral, elas estão em cumprimento de pena em meio aberto na cidade de São Paulo ou respondem ao processo em liberdade.

Nos últimos anos, em razão do reconhecimento e efetivação de direitos das mulheres migrantes em conflito com a lei, por exemplo, em matéria de execução penal e regularização migratória, o número de mulheres migrantes egressas que vivem na cidade de São Paulo tem aumentado consideravelmente ${ }^{5}$, e com isso surgem diariamente novas demandas e novos desafios, relatos de violaçōes de direitos e dificuldades específicas no acesso a serviços e às políticas públicas municipais.

Embora a nova Lei de Migração (Lei 13.445/2017) tenha representado um importante passo no sentido de reconhecer as pessoas de outros países envolvidas com o sistema penal nacional como migrantes e sujeitos de direito no território brasileiro, ainda há muitos desafios em sua implementação na prática que acabam repercutindo na realidade dessas pessoas e trazendo diversos empecilhos em seu cotidiano.

\section{BREVE PANORAMA DO ENCARCERAMENTO DE MULHERES MIGRAN- TES NA CIDADE DE SÃO PAULO}

São Paulo é o município do Brasil que mais aprisiona mulheres não brasileiras em vista dos fluxos das atividades ilícitas relacionadas à drogas, o que tem se dado especialmente em razão da proximidade com o Aeroporto Internacional de Guarulhos e à política de concentraçáo das mulheres de outras nacionalidades em estabelecimentos penais específicos da capital adotada pela administração penitenciária paulista .

\footnotetext{
4 Sobre o início do Projeto Migrantes Egressas apoiado pelo Fundo de Direitos Humanos dos Países Baixos: <http://ittc.org.br/ittc-apresenta-seu-novo-projeto-egressas/>.

5 A partir do acesso às listas mensais das duas unidades que concentram o maior número de mulheres migrantes privadas de liberdade, a Penitenciária Feminina da Capital (PFC) e o Centro de Progressão Penitenciária do Butantã (CPP-Butantâ), foi possível contabilizar que cerca de 450 mulheres migrantes tornaram-se egressas do sistema prisional paulistano entre os anos 2017-2018, tanto devido ao acesso à medidas cautelares enquanto respondem a processo criminal, quanto durante a execução de suas penas, especialmente pelo acesso à liberdade condicional e regime aberto.
}

6 BUMACHAR, B. Nem dentro, nem fora: a experiência prisional de estrangeiras em São Paulo. 2016, p. 74. 
De acordo com levantamentos do Departamento Penitenciário Nacional (Depen) e com os dados registrados pelo ITTC ao longo do período de trabalho junto a essa população, nos últimos anos, o número de mulheres migrantes presas na cidade de Sáo Paulo tomou diferentes proporçóes, chegando a mais de 500 em $2013^{7}$ e, atualmente, há aproximadamente 250 mulheres migrantes em prisão provisória ou regimes fechado e semiaberto em duas unidades prisionais na cidade, a Penitenciária Feminina da Capital e o Centro de Progressão Penitenciária Feminino do Butantã.

Os dados oficiais do Levantamento de Informações Penitenciárias mais recentes, ${ }^{8}$ demonstram que, em junho de 2016, 63\% das 529 mulheres não brasileiras em situação de prisão no Brasil - provenientes de diversos países da América Latina, África, Ásia e Europa -, encontravam-se no estado de São Paulo. Os continentes e dados gerais apresentados pelo Levantamento refletem basicamente a população de migrantes reclusas neste estado, o que em 2016 correspondia a um total de 335 mulheres.

Nos anos 2000, quando do início de sua atuação, o ITTC estima que havia cerca de 40 mulheres migrantes presas em São Paulo ${ }^{9}$. Após a edição da nova Lei de Drogas (Lei 11.343/2006) brasileira em 2006, conforme apontam os dados do Depen, este número saltou para 362 em junho de 2007 e 424 em dezembro do mesmo ano, o que permite concluir que o crescimento do aprisionamento de mulheres migrantes no estado está diretamente atrelado ao endurecimento da criminalização das condutas relacionadas a drogas como um movimento contemporâneo no Brasil e no mundo ${ }^{10}$.

Por outro lado, as atividades ilegais domésticas e transnacionais relacionadas às drogas cresceram também nos contornos do que Alba Carosio" ${ }^{11}$ descreve como "feminização da sobrevivência”, de modo que a necessidade de sobrevivência das mulheres e de seus núcleos familiares é fator preponderante para o surgimento de modalidades de trabalho informais, assim como modalidades de pessoas trabalhadoras genéricas e descartáveis, tais como as funçóes exercidas pela maioria das mulheres no que tange ao comércio e transporte transnacional de drogas.

A pesquisadora Corina Giacomello ${ }^{12}$ define que o grupo conhecido como "mulas" de drogas é caracterizado por um grupo heterogêneo de mulheres de diferentes origens culturais e socioeconômicas de distintas nacionalidades. A trajetória das mulheres acompanhadas

\footnotetext{
CUNHA, I. R. T. Gênero, migração e criminalização: fronteiras e deslocamentos nas trajetórias de mulheres migrantes em conflito com a lei em São Paulo. São Paulo, 2018, p. 76.

8

BRASIL, 2018

$9 \quad$ INSTITUTO TERRA, TRABALHO E CIDADANIA. De estrangeiras a migrantes: os 15 anos de luta do Projeto Estrangeiras. São Paulo: 2016, p. 16.

10 OLIVEIRA, N.; SESTOKAS, L. A política de drogas é uma questáo de mulheres. In: Revista Sur, 2018, p. 155.

11 CAROSIO, A. Feminismo Latinoamericano: Imperativo ético para la emancipación. In: Gênero y Globalización, 2009, p. 238.

12 GIACOMELLO, C. Género, drogas y prisión: Experiencias de mujeres privadas de su liberdad en Mexico. Tirant lo Blanch, Mexico D.F., 2013, p. 6.
} 
pelo ITTC dentro e fora da prisão em geral está ligada à definição da autora no que concerne a este grupo específico de pessoas que é criminalizada por realizarem o transporte transnacional de drogas e que, costumeiramente, não possuem antecedentes penais, além de serem também as responsáveis pelo sustento de seus núcleos familiares em seus países maternos.

Ao mesmo tempo que o número de mulheres migrantes no sistema prisional paulista foi se alterando nos últimos anos, apresentando uma significativa elevação até 2013 e um decréscimo paulatino desde entáo - como indicam os dados do já mencionados do Depen e como se pode verificar pela atuação cotidiana do ITTC ${ }^{13}$-, o número de mulheres migrantes egressas da prisão só veio aumentando neste período, sobretudo a partir de novos fatores relativos ao acesso a direitos: medidas cautelares e medidas alternativas à prisão, progressão de regime de cumprimento de pena, reconhecimento de direitos da execução penal, como a liberdade condicional, acesso à documentação brasileira e regularização migratória, entre outras situaçôes que viabilizaram a continuidade do cumprimento de pena em meio aberto e até mesmo a aplicação de penas distintas da privação de liberdade ${ }^{14}$.

Conforme ressalta Natália Corazza Padovani ${ }^{15}$, embora os trânsitos decorrentes do comércio e transporte de drogas não estejam diretamente relacionados a uma intencionalidade de migrar, a detenção e o tempo da pena a cumprir em outro país abrem possibilidades e perspectivas migratórias, de modo que a prisão transnacional deve também ser compreendida como fluxo migratório. Neste contexto, ao saírem da prisão, mulheres migrantes buscam formas de se manterem no Brasil, muitas vezes porque judicialmente precisam permanecer no país até o término de suas penas, mas igualmente porque em outras situaçóes o tempo de prisão e o de pena a cumprir em meio aberto podem gerar rearranjos e novas expectativas de vida no Brasil.

\section{O IMPACTO DA LEI DE MIGRAÇÃO (LEI 13.445/2017) NO ACESSO A DI- REITOS POR MULHERES MIGRANTES EM CONFLITO COM A LEI}

A atual Lei de Migração brasileira ${ }^{16}$ é uma conquista fruto de anos de trabalho e articu-

\footnotetext{
13 O embasamento desta informação na atuação cotidiana do ITTC se dá em vista da periodicidade que o instituto solicita listas mensais às penitenciárias que concentram mulheres imigrantes privadas de liberdade na cidade de São Paulo, de modo que a atuação prática do ITTC viabiliza um monitoramento ativo das entradas e saídas de mulheres náo brasileiras dos estabelecimentos prisionais em São Paulo e acaba por organizar dados quantitativos com atualização praticamente mensal quando comparados aos dados estatísticos do Levantamento de Informaçóes Penitenciárias (Infopen) que costumam ser anuais.
}

14 INSTITUTO TERRA, TRABALHO E CIDADANIA. De estrangeiras a migrantes: os 15 anos de luta do Projeto Estrangeiras. São Paulo: 2016.

15 PADOVI, N. C. Sobre casos e casamentos: afetos e "amores" através de penitenciárias femininas em São Paulo e Barcelona, 2015.

16 BRASIL. Lei no 13.445 de 2017. 
lação das organizaçóes da sociedade civil, dentre elas o ITTC, coletivos de migrantes no Brasil, com a academia, organismos internacionais, órgãos governamentais e parlamentares. A nova lei se propóe a nortear a política migratória brasileira a partir do viés da proteção dos direitos humanos. Orientada pelos princípios da igualdade, não discriminação e não criminalização da migração, a Lei deixa de lado o paradigma da segurança nacional que orientava a legislação anterior, o Estatuto do Estrangeiro de $1980^{17}$.

Tal caráter é essencial para reforçar a importância desta Lei, no que concerne às mulheres migrantes em conflito com a lei, já que pela primeira vez na história do Brasil uma legislação federal garante e reconhece status migratório para pessoas não brasileiras envolvidas com o sistema penal ${ }^{18}$, estabelecendo a não criminalização da migração como um dos princípios da política migratória brasileira ${ }^{19}$.

A atual Lei de Migração passou a reconhecer as pessoas não brasileiras com antecedentes penais não mais como estrangeiras, mas sim como migrantes. A denominação de pessoas não brasileiras como "estrangeiras" utilizada pelo Estado, principalmente em relação àquelas "em conflito com a lei", demarca uma atuação seletiva do Estado ao tentar determinar aqueles e aquelas que podem ou náo migrar para o Brasil ${ }^{20}$. Enquanto a pessoa estrangeira é a "estranha", a que vem de fora e que, portanto, não possui elo com o novo território, a migrante, por sua vez, está mais associada ao restabelecimento e fixação em um novo espaço, o que, no plano institucional e da garantia de direitos, a torna um sujeito de direitos mais legítimo.

Ter antecedentes penais no Brasil nem sempre implicou no reconhecimento jurídicosocial das pessoas não brasileiras como migrantes sujeitas de direitos no país, já que a política criminal nacional direcionada às pessoas de diferentes países, exposta por meio do Estatuto do Estrangeiro, legislação proveniente do período da ditadura civil-militar brasileira, passou a se mesclar com a política de guerra às drogas ${ }^{21}$. A mudança legislativa, por meio da Lei de Migraçôes e a adoção do termo "migrantes", objetiva a garantia de igualdade de direitos entre todas as pessoas migrantes e o reconhecimento de direitos inclusive àqueles envolvidos com o sistema penal.

Até 2013, essas pessoas raramente conseguiam cumprir medidas alternativas ou penas

$17 \quad$ BRASIL. Lei no 6.815 de 1980.

18 Este reconhecimento pode ser exemplificado pelo artigo 30, II, h da Lei de Migraçóes que regula as hipóteses de autorização de residência para pessoas migrantes. Neste sentido: "Art. 30. A residência poderá ser autorizada, mediante registro, ao imigrante, ao residente fronteiriço ou ao visitante que se enquadre em uma das seguintes hipóteses: (...) II - a pessoa: (...) h) esteja em liberdade provisória ou em cumprimento de pena no Brasil". Neste sentido, este artigo explicita igualmente que a importância do reconhecimento destas pessoas como migrantes está principalmente na possibilidade de regularização migratória enquanto respondem processo criminal no país e durante todo o cumprimento de pena.

19 O princípio da não criminalização da migração encontra-se descrito no artigo 3º, III da Lei de Migrações.

20 INSTITUTO TERRA, TRABALHO E CIDADANIA. De estrangeiras a migrantes: os 15 anos de luta do Projeto Estrangeiras. São Paulo: 2016, p. 10.

21 MORAES, A. L. Z. Crimigração: A relação entre política migratória e política criminal no Brasil. Porto Alegre: 2016, p. 247. 
fora da prisão justamente pela impossibilidade de se regularizarem no território nacional, pela existência do procedimento de expulsão $\mathrm{o}^{22}$ e pela presumida ausência de vínculos com o país ${ }^{23}$. Apesar da legislaçáo prever o regime progressivo para a pena privativa de liberdade, e do princípio constitucional da igualdade entre indivíduos brasileiros e não nacionais, essas pessoas acabavam cumprindo suas sentenças integralmente em regime fechado e eram expulsas a seus países de origem imediatamente após o término da pena. Quando seus direitos eram reconhecidos e elas conseguiam sair da prisão para cumprir o restante da pena em liberdade, elas ficavam em um limbo em relação à situação migratória, sendo obrigadas a permanecerem no país, mas sem permissão para acessar algum tipo de visto ou regularização.

Em 2014, a Resolução 110 do Conselho Nacional de Imigração ${ }^{24}$ passou a permitir a permanência e, consequentemente, a regularização provisória para migrantes em cumprimento de pena, e contornou parte do problema. Com a nova medida, a qual foi incorporada pela atual lei federal, as pessoas migrantes em cumprimento de pena passaram a obter a documentaçáo nacional, tendo mais chances de acessar o mercado de trabalho formal e viver de forma mais digna e menos vulnerável na cidade.

Neste sentido, cabe ressaltar que a extrema maioria das mulheres acompanhadas pelo ITTC dentro e fora da prisão são as únicas ou principais responsáveis pelo sustento de seus lares em seus países de origem. Em nossa experiência de atuação no acompanhamento da aplicação da Lei de Migração durante os últimos dois anos, foi possível observar que o acesso à documentação brasileira permite, por exemplo, que mulheres migrantes que

\footnotetext{
22 A expulsão pode ser definida conforme a atual Lei de Migraçóes em seu artigo 54 como: "A expulsão consiste em medida administrativa de retirada compulsória de migrante ou visitante do território nacional, conjugada com o impedimento de reingresso por prazo determinado."

23 Este posicionamento, por exemplo, pode ser observado através do seguinte julgado do Supremo Tribunal Federal (STF): "Habeas corpus. Execução penal. Decreto de expulsão de estrangeiro. Pedido de livramento condicional. Inadmissibilidade. Ordem denegada. 1. É firme a jurisprudência deste Supremo Tribunal no sentido de que o decreto de expulsáo, de cumprimento subordinado à prévia execuçáo da pena imposta no País, constitui empecilho ao livramento condicional do estrangeiro condenado. 2. A análise dos requisitos para concessão do benefício de livramento condicional ultrapassa os limites estreitos do procedimento sumário e documental do habeas corpus. 3. Ordem denegada. (HC n. ${ }^{\circ}$ 99.400, Relatora a Ministra Cármen Lúcia, DJe de 27/5/2010.)". Da mesma forma, o Superior Tribunal de Justiça (STJ) também manteve consolidado por anos o entendimento no sentido de afastar a possibilidade de progressão de regime para pessoas náo brasileiras em conflito com a lei: "Processual penal. Habeas corpus. Tráfico de drogas. Associaçáo para o tráfico. Progressão de regime. Paciente estrangeiro. Decreto de expulsão. Regime mais rigoroso. Possibilidade. Ordem denegada. 1. Este Superior Tribunal já pacificou o entendimento no sentido de não ser possível deferir ao estrangeiro o benefício da progressão de regime prisional quando, contra ele, já houver processo de expulsão em andamento. 2. Ordem denegada. (HC 90.662/MT, Relator o Ministro Arnaldo Esteves Lima, DJe de 20/10/2008)".

24 Antes da aprovação da nova Lei de Migraçóes, a Resolução Normativa 110 do Conselho Nacional de Imigração (CNIg), publicada no Diário Oficial da União em abril de 2014 e regulamentada pela Portaria $\mathrm{n}^{\circ} 6 \mathrm{em}$ janeiro de 2015, passou a prever procedimento administrativo de regularização migratória para pessoas migrantes em conflito com a lei. O texto da Resoluçáo e da Portaria autorizavam a concessão de permanência provisória, a título especial, para pessoas de outras nacionalidades que cumpriam pena ou respondiam a processo criminal no Brasil, especificando documentaçóes e procedimentos para obtençáo do protocolo de permanência e, consequentemente, documentos como Carteira de Trabalho e Previdência Social (CTPS) e Cadastro da Pessoa Física (CPF). Disponível em: <https://www.legisweb.com.br/legislacao/?id=269310>. Acesso em 06 dez. 2018.
} 
respondem processo criminal ou cumpram pena em meio aberto tenham condiçóes de realizar uma busca mais qualificada por empregos no Brasil e possam permanecer apoiando economicamente seus núcleos familiares à distância.

É indubitável que a Lei de Migraçôes representa uma série de avanços para a política migratória brasileira, porém é imprescindível também ressaltar que ao mesmo tempo o Decreto regulamentador ${ }^{25}$ desta nova legislação foi aprovado pelo Poder Executivo com participação bastante limitada da sociedade civil e apresenta-se contrário à própria Lei em alguns pontos, como da previsão de prisão em casos de efetivação de medidas de retirada compulsória ${ }^{26}$, como é o caso da expulsão, além de apresentar sérias lacunas postergando para "atos ministeriais futuros" os critérios e condiçôes para acesso a direitos por pessoas migrantes, o que tem fragilizado a aplicabilidade da nova lei e pode mitigar seu caráter garantista, sobretudo diante do cenário com o novo Executivo Federal eleito no país.

No âmbito municipal, ainda é importante ressaltar que o município de São Paulo, desde 2016, possui uma legislação específica de políticas públicas para pessoas migrantes - Lei $\mathrm{n}^{\circ} 16.478 / 2016$ e, no poder legislativo municipal, está em andamento o projeto de lei 00537/2017, que se propóe a instituir uma Política Municipal de Atendimento às Pessoas em Restrição de Liberdade e Egressas, legislações que possuem potencial de impacto direto na garantia de direitos de mulheres migrantes egressas do sistema prisional e que vivem na cidade de Sáo Paulo. No entanto, embora se reconheçam os avanços, nota-se que na prática ainda é muito problemático o cruzamento entre estas situações de prisão e migração, sempre delimitadas a partir de recortes de gênero, raça, classe, nacionalidade e outras categorias de diferenciação.

Pelo exposto, o monitoramento do acesso a direitos e da implementação da nova política migratória brasileira é uma das atividades prioritárias do ITTC, principalmente do Projeto Migrantes Egressas. A metodologia de atuação do PME evidencia que apenas por meio do acompanhamento direto de mulheres em conflito com a lei quando buscam acessar serviços públicos, como os serviços da Polícia Federal e os de atenção a migrantes, possibilita diagnosticar as reais dimensôes do impacto da lei, de seu decreto regulamentador e portarias no cotidiano das pessoas migrantes no Brasil. Esta atuação de base através de acompanhamentos de casos individuais viabiliza a compreensáo das instituiçóes e atores envolvidos para buscar a soluçâo de problemas que decorrem da violaçấo de direitos na prática das instituiçôes e se situam em contramão às disposições da Constituição Federal e da nova legislação.

Dadas as novas possibilidades trazidas neste campo, um exemplo da possibilidade de acompanhar a aplicação (ou não) da atual lei de migraçôes para pessoas migrantes em conflito com a lei, está relacionado ao acesso à regularização migratória. Neste sentido, o PME auxilia as mulheres acompanhadas para a obtenção de todos os documentos necessários durante o tempo de cumprimento de pena fora dos estabelecimentos prisio-

\footnotetext{
$25 \quad$ Brasil. Decreto mo 9.199 de 2017

26 Esta hipótese encontra-se disposta no artigo 211 do Decreto no 9.199/2017: "O delegado da Polícia Federal poderá representar perante o juízo federal pela prisão ou por outra medida cautelar, observado o disposto no Título IX do Decreto-Lei no 3.689, de 3 de outubro de 1941 - Código de Processo Penal.”
} 
nais, bem como quando têm filhas ou filhos nascidos no Brasil ou quando terminam o cumprimento de pena, mas ainda estão aguardando atualizaçóes sobre seus processos de expulsão.

Um dos principais problemas de aplicação da lei que identificamos na prática é que a autorização de residência para pessoas em liberdade provisória e em cumprimento de pena requer uma série de documentaçóes e, dentre elas, há a exigência de apresentação de declaração que ateste os antecedentes penais de cada pessoa no local em que tenha residido nos últimos 5 anos, o que em geral costuma ser o país materno das mulheres que atendemos ${ }^{27}$. A exigência deste documento mostra-se como um obstáculo real à regularização migratória, já que nem sempre os Consulados e Embaixadas podem fornecer este documento estando aqui no Brasil, além de ser um documento que costuma ser custoso para ser emitido e traduzido, o que inviabiliza que muitas mulheres migrantes o obtenham em razão das dificuldades econômicas que também enfrentam.

Outro exemplo da realidade identificada e analisada pelo ITTC que se relaciona diretamente com o atendimento realizado com mulheres em situação de prisão, egressas e a política migratória brasileira diz respeito àquelas que, embora acusadas e condenadas pela conduta ilícita de transporte transnacional de drogas, são também mulheres que em outras condiçóes de migração para o Brasil poderiam vir a ser reconhecidas pelo Estado brasileiro como refugiadas, vítimas de tráfico de pessoas ou que realizaram o transporte de drogas por motivos de crise econômica e social em seus países. No entanto, observa-se que as políticas mundiais de repressão às drogas reproduzidas também pelo Brasil inviabilizam um olhar de proteção ao contexto integral de vida destas mulheres como migrantes e de suas trajetórias até chegarem ao Brasil ${ }^{28}$.

A linha de continuidade entre o trabalho semanal realizado pelo ITTC dentro das penitenciárias paulistanas que concentram a populaçáo de mulheres migrantes presas e a criação de um vínculo que permite estender este trabalho para além da prisão, para quando as mulheres atingem diferentes formas de liberdade no Brasil, é a chave para a consolidação de formas de diálogo público que viabilizem a construção e articulação de redes institucionais de apoio e acesso a direitos para mulheres migrantes em conflito com a lei tanto dentro quanto fora dos estabelecimentos penais.

\footnotetext{
$27 \quad$ A exigência de apresentação dos antecedentes criminais do país de origem, assim como os demais documentos requeridos para solicitação de autorização de residência de pessoa imigrante que se encontra em liberdade provisória ou cumprimento de pena, estão determinadas pela Portaria Interministerial no 3 de 27 de fevereiro de 2018.

28 Um exemplo do impacto das políticas mundiais de repressão às drogas e da escolha política de não proteção às pessoas migrantes quando condenadas por condutas relacionadas a drogas é a causa de exclusão que consta na Lei 9.474 de 22 de julho de 1997, a qual define os mecanismos para a implementaçáo do Estatuto dos Refugiados de 1951. Neste sentido, o artigo 3º, III da referida Lei dispóe que não serão beneficiadas da condição de refugiadas as pessoas que, dentre outras condutas ilícitas enumeradas, tenham praticado "tráfico de drogas".
} 


\section{O INÍCIO DO PROJETO MIGRANTES EGRESSAS (PME), METODOLOGIA E DADOS GERAIS DE ATENDIMENTO}

O Projeto Migrantes Egressas (PME) deu início às suas atividades em março de 2017 e encerrou seu primeiro ciclo de dois anos em abril de $2019^{29}$. Como já tratado no decorrer deste artigo, o PME é fruto do trabalho do Projeto Estrangeiras que, desde $2001^{30}$, tem entrado semanalmente em unidades prisionais femininas da cidade de São Paulo onde se encontram custodiadas mulheres náo nacionais para atendê-las diretamente e assisti-las principalmente no que diz respeito à comunicação com suas famílias e na orientação em relação aos seus processos e direitos. Por conta deste trabalho já consolidado e do acolhimento realizado com as mulheres, o ITTC se transformou em um espaço de referência também para quando essas mulheres se tornam egressas.

Os dois anos do PME, construído a partir da atuação dos mais de 17 anos de atuação do Projeto Estrangeiras, propiciaram a consolidação de uma metodologia de atendimento direto à mulheres migrantes em conflito com a lei ${ }^{31}$. Essa metodologia está pautada no atendimento integral das mulheres que buscam o ITTC para o acolhimento e resolução de suas demandas - o atendimento integral significa que a partir da busca espontânea pelo atendimento, a equipe foca na identificação e compreensão da demanda trazida, considerando que esta nem sempre vem expressa na primeira fala-.

A base da metodologia de atendimento está dividida em quatro momentos distintos, porém complementares e muitas vezes, concomitantes entre si: o primeiro momento é o de acolhimento; o segundo momento é o de escuta ativa das demandas e compartilhamento de informaçóes; o terceiro momento é o de encaminhamento das demandas e acompanhamento de sua resolução; e por fim, o quarto é a orientação e educação para a autonomia. Além disso, a metodologia elenca as principais demandas das mulheres, acompanhadas de situaçóes exemplificativas passadas pela equipe (moradia e abrigamento, acompanhamento processual, regularização migratória e documentos relacionados, solicitação de refúgio, expulsão, capacitação, trabalho, saúde, demandas diversas de assistência social e relacionadas às unidades prisionais); por fim apresenta as conclusóes e uma síntese de dez recomendaçóes para atuaçáo junto a mulheres migrantes em conflito com a lei ${ }^{32}$.

Nos vinte e oito meses de projeto - contabilizados de março de 2017 a abril de 2019 - o PME realizou mais de 1.700 atendimentos às mulheres migrantes em conflito com a lei,

\footnotetext{
29 O encerramento do primeiro ciclo do PME foi marcado por um evento de encerramento e pelo lançamento das 10 recomendações para atuação junto a mulheres migrantes em conflito com a lei, disponível em: <http://ittc.org.br/10-recomendacoes-atuacao-mulheres-migrantes-em-conflito-com-lei/>. Acesso em 08 jul. 2019.

30 Ano de formalização e reconhecimento do trabalho do ITTC pelo Estado de São Paulo, quando foi firmado pela primeira vez o protocolo de intençóes entre o ITTC e a Secretaria da Administração Penitenciária (SAP).

31 O documento que sintetiza a metodologia de atendimento do ITTC foi intitulado como "Caminhos da liberdade: orientaçóes para o atendimento a mulheres migrantes em conflito com a lei”. Até o momento de envio deste artigo o documento ainda náo havia sido publicado.

$32 \quad$ Vide nota de rodapé número 28.
} 
conforme se pode depreender do gráfico intitulado como "Número de atendimentos diretos realizados por mês (2017-abril/2019)".

Números de atendimentos diretos realizados por mês (2017-abril/2019)

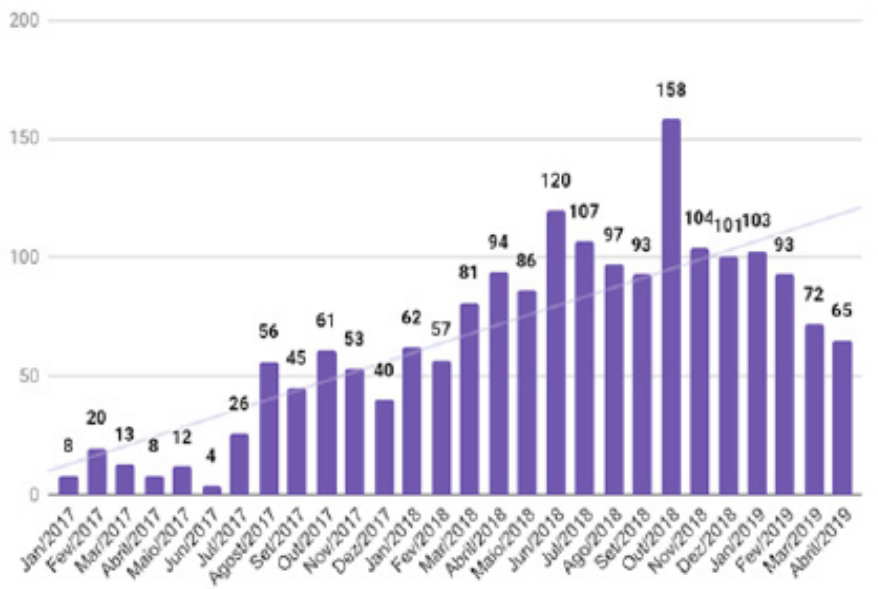

Estes atendimentos foram realizados no escritório do ITTC $^{33}$, espaços externos ${ }^{34}$ e por meio das redes sociais, e-mail e telefone. No que se refere aos atendimentos externos, pode-se dividi-los em: acompanhamento direto das mulheres para atendimento e resolução de demandas em órgãos públicos (fóruns, Polícia Federal, setor de Administração Penitenciária, Unidade Básica de Saúde, etc.) e visitas a espaços de acolhimento que estão residindo ${ }^{35}$.

De modo geral, estima-se que mais de 257 mulheres migrantes procuraram o ITTC como espaço de atendimento, acolhimento, resolução de demandas e dúvidas sobre documentação, acolhimento em abrigos públicos, andamento de processo criminal, dentre outras situaçóes. Sendo que durante os 28 meses do PME o ITTC realizou uma média de atendimento mensal de 40 mulheres migrantes.

\footnotetext{
33 Os atendimentos realizados no ITTC subdividem-se em: atendimentos individuais e atendimentos em grupo com representantes consulares, mulheres atendidas e equipe do ITTC.

34 Importa esclarecer que os atendimentos externos são realizados diante de casos específicos como, por exemplo, de mulheres mães e gestantes, com maior dificuldade de domínio da língua, etc. Trata-se principalmente do acompanhamento das mulheres migrantes a órgãos públicos, a fim de compreender como tem se dado seu acesso a direitos nestes espaços e o reconhecimento das especificidades por elas serem mulheres migrantes egressas do sistema prisional brasileiro.

35 Dentre os espaços de acolhimento visitados estão: Centro de Acolhida Especial para Mulheres Imigrantes (Caemi), Centro de Acolhida Aparecida (C.A Aparecida), Centro de Acolhida Maria Maria (C.A Maria Maria), Centro de Acolhida para Imigrantes - Pari e Centro de Acolhida para Imigrantes - Bela Vista.
} 
O gráfico intitulado "Número de Mulheres atendidas por mês (2017-2019) ilustra a variação mensal de mulheres atendidas mês a mês a partir de janeiro de 2017 até maio de 2019.

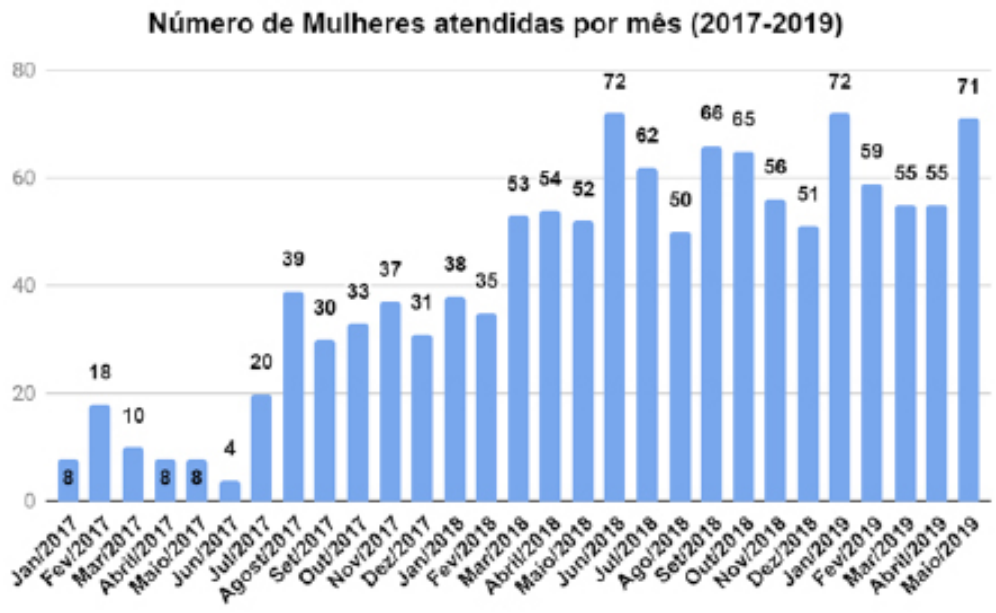

Observa-se que houve um aumento substancial na quantidade de atendimentos diretos realizados pelo ITTC desde o início do projeto. O diagnóstico atrelado a este aumento relaciona-se à sistematização e organização do projeto, assim como também à ampliação da comunicação da equipe com as mulheres a partir de diferentes meios de comunicação, o que muitas vezes acaba por significar uma ampliaçáo das possibilidades de atendimento frente às dificuldades básicas enfrentadas por elas e por muitas das pessoas que vivem nas periferias da cidade de São Paulo e que não contam com viabilidade financeira para utilizar o transporte público e, assim, acabam náo acessando o centro da cidade e muitos dos serviços ali localizados.

No que se refere ao conteúdo dos atendimentos realizados, o instituto denominou como marcadores por tipo de atendimento as principais questôes trazidas nos atendimentos e que são mediadas pelo projeto, que, além de encaminhar os pedidos aos órgãos competentes, procura acolher as mulheres e prestar orientaçóes com o propósito de garantir ferramentas para que elas possam desenvolver sua autonomia e se apropriar de seus direitos e processos para buscar a resolução de seus casos. Um exemplo dessa atuação é no tocante ao acompanhamento de processos judiciais: acessamos os andamentos dos processos de conhecimento e execução penal e informamos as mulheres acerca das atualizaçôes de seus casos individuais, verificamos a possibilidade de requerer determinados direitos, tais como o indulto (perdáo da pena) e as progressóes de regime, e as orientamos acerca das medidas a serem tomadas para alcançá-los.

Depreende-se do gráfico intitulado "Marcadores por tipo de atendimento (2017-2019)" que as duas principais demandas apresentadas foram referentes ao acesso a informaçóes processuais $(31.9 \%)$ e acesso à documentação pessoal brasileira $(28,45 \%)$. Ressalta-se que o indicador "outros" (6.4\%) refere-se às demandas de natureza diversa, apresentadas durante os atendimentos, como por exemplo: orientação e agendamento para retirada de 
pecúlio na unidade prisional, informaçóes a respeito de visitas a pessoas em situação de prisão, dentre outras.

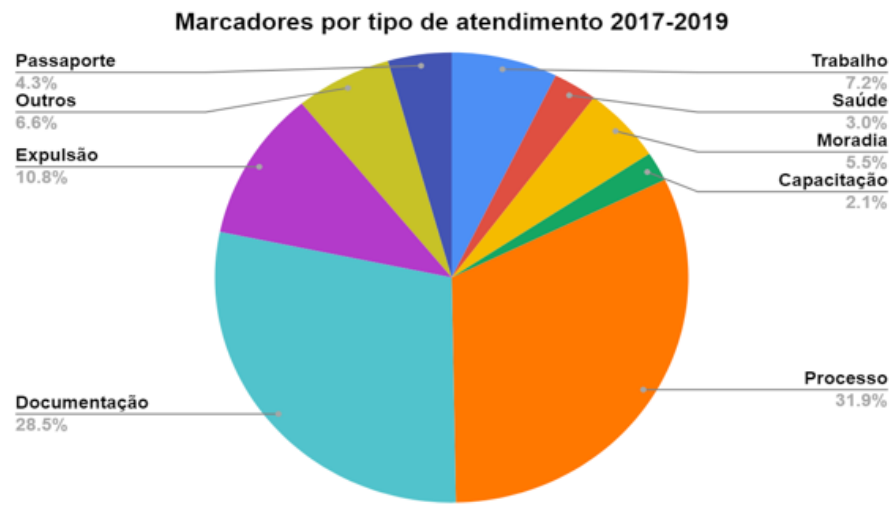

$\mathrm{Na}$ grande maioria dos casos, a partir das demandas trazidas, promovemos a mediação do diálogo das mulheres com as Defensorias Públicas da União e do Estado, advogados e advogadas, serviços públicos em geral, assim como Consulados e Embaixadas. A atuação do ITTC, assim, também se configura como intérpretes das legislações, procedimentos e práticas para as mulheres, além de auxiliá-las a selecionar as informaçóes e narrativas a levar a cada instituição responsável por atendê-las.

\section{REFLEXÓES SOBRE INTERSECÇÓES ENTRE A JUSTIÇA CRIMINAL E O ACESSO A DIREITOS BÁSICOS A MULHERES MIGRANTES EM CONFLITO COM A LEI}

O trabalho de acompanhamento dentro e fora da prisão permite ao ITTC ter contato com histórias de mulheres que, em geral, estão sendo acusadas por atividades transnacionais relacionadas a drogas e que relatam as motivaçóes que as trouxeram até ao Brasil, suas vivências no cárcere e também após ele.

A intersecção entre uma série de marcadores sociais da diferença como raça, classe, gênero, idade, nacionalidade, sexualidade com os antecedentes criminais ressoam diretamente em restriçóes, violaçóes e também luta por direitos básicos para mulheres migrantes em conflito com a lei. Por estes fatores, a seguir serão apresentadas breves reflexôes práticas sobre o acesso a direitos básicos como moradia e saúde no município de Sáo Paulo para mulheres migrantes em conflito com a lei e também serão apresentadas breves proposiçóes de mudanças possíveis nestas áreas.

A grande maioria das mulheres migrantes em conflito com a lei não possuem residência fixa no Brasil e, em razão disso, ao saírem da unidade prisional, encontram-se em situação 
de rua. A ausência de vínculos prévios com o Brasil faz com que elas dependam diretamente do funcionamento das políticas municipais de assistência social para acessar vagas em abrigos municipais ${ }^{36}$.

Os fluxos mais comuns de acesso aos serviços de abrigamento que o ITTC acompanha está relacionado ao território da zona leste da cidade, onde se localiza o Caemi - Centro de Acolhida Especial para Mulheres Imigrantes -, no bairro da Penha, gerenciado pela Congregação das Irmâs Palotinas em convênio com a Prefeitura Municipal de São Paulo. O centro de referência da política de assistência na região é o Centro de Referência Especializado de Assistência Social da Penha (Creas Penha) que recebe e faz um atendimento inicial com as mulheres e, caso haja vaga disponível, as encaminha para o referido abrigo. O Caemi é um dos únicos abrigos públicos que permite que as mulheres acolhidas lá, mesmo quando não estão com seus filhos ou suas filhas, permaneçam no espaço durante todo o dia ${ }^{37}$.

Elas têm grandes dificuldades de acesso a esses centros - em situaçóes emergenciais quando necessitam de abrigos públicos - em razão do funcionamento em horário comercial. Muitas vezes o cumprimento do alvará de soltura, nas unidades prisionais, é feito no fim da tarde, e elas são levadas obrigatoriamente à sede da Polícia Federal para fins de registro migratório, saindo de lá tarde da noite. Neste sentido, para buscar a solução deste gargalo específico no âmbito do abrigamento propôe-se:

"Recomendação no 7. Estabelecer um protocolo de atendimento integrado entre o sistema judicial e as políticas penitenciárias e de assistência para que as pessoas sem residência fixa que deixam as unidades prisionais possam ser diretamente encaminhadas para as vagas disponíveis em centros de acolhida, caso necessário, evitando assim a sua sujeição a situações de violaçóes e ampliação da vulnerabilidade, com especial atenção aos casos de mulheres migrantes gestantes e com crianças até 6 meses de idade ${ }^{38}$."

O impacto da passagem pelo sistema prisional também se manifesta em inúmeras outras

\begin{abstract}
36 A rede municipal de acolhimento na cidade de São Paulo funciona a partir das diretrizes da Secretaria Municipal de Assistência e Desenvolvimento Social (SMADS), ou seja, todos os serviços de assistência social, exceto o serviço do Centro de Referência e Atendimento para Imigrantes (CRAI), estão subordinados aos regramentos e, consequentemente, ao fluxo de funcionamento da rede preestabelecido pela SMADS. No município de Sáo Paulo há espaços de acolhimento de pernoite de 16h, de permanência de $24 \mathrm{~h}$ e os centros de acolhida especiais. Há nove centros de acolhida específicos para mulheres, sendo que um deles é o Centro de Acolhida Especial para Mulheres Imigrantes (Caemi), os demais centros de acolhida são mistos ou acolhem apenas homens. Disponível em: <https://www.google.com/maps/d/u/0/viewer?mid=11XOg0nmKspE3LelC1usYKGey9F8\&ll=-23.551609599999985\%2C-46.64658689999993\&z=18>. Acesso em: 11 mar. 2019.

37 Resguardadas as experiências e trajetórias individuais das mulheres que acompanhamos, é comum ouvirmos relatos de mulheres que identificam na estrutura de funcionamento dos centros de acolhimento características similares às das estruturas prisionais que elas vivenciaram, especialmente em vista dos regramentos que organizam o dia-a-dia desses serviços.
\end{abstract}

38 INSTITUTO TERRA, TRABALHO E CIDADANIA. De estrangeiras a migrantes: os 15 anos de luta do Projeto Estrangeiras. São Paulo: 2016. 
ocasióes. Apesar de os atendimentos de saúde realizados dentro das prisóes estarem vinculados ao Sistema Único de Saúde (SUS), ao deixarem os estabelecimentos, as mulheres não levam consigo o cartão do SUS ou seu próprio prontuário médico. Embora já tenham cadastro, ao necessitar acessar a saúde fora da prisão, elas precisam solicitar o cartão SUS outra vez para somente então poderem agendar os atendimentos:

\begin{abstract}
"Recomendação no 6. Garantir que mulheres migrantes saiam das unidades prisionais com sua carteira de identificação no Sistema Único de Saúde (SUS) e que possam ter acesso, caso desejado, a todo seu histórico de atendimento médico no sistema prisional (prontuário) ou, subsidiariamente, realizar o encaminhamento deste histórico para a Unidade Básica de Saúde (UBS) de referência da localidade em que estas mulheres estiverem residindo no momento pós-cárcere ${ }^{39}$."
\end{abstract}

Por sua vez, os atendimentos de assistência social realizados dentro do sistema prisional sequer estão atrelados às políticas de assistência, de modo que é ainda mais difícil uma articulação do acesso a tais políticas dentro e fora dos estabelecimentos penais. Assim, ao saírem da prisão, as mulheres acompanhadas precisam dar início a diversos procedimentos para poderem acessar direitos básicos que poderiam ter sido já iniciados dentro da prisão, aproveitando que elas já estavam institucionalizadas, mas não são, por falta de articulação dos serviços e políticas públicas para pessoas em privação de liberdade.

Há também outras situaçóes vivenciadas por mulheres egressas que, ao procurarem serviços como de acesso à documentação civil, sem ter conhecimento da interligação entre sistemas de identificação e segurança pública, foram presas após acionamento de autoridade policial pelo próprio órgão público quando estes identificam nos sistemas de informação a existência de decisóes judiciais de prisão pendentes de cumprimento. Essas situaçóes muitas vezes trazem desdobramentos complexos para a vida de mulheres que já vivem no Brasil há muitos anos e por desconhecimento do funcionamento da justiça brasileira wacabam sendo presas novamente e tendo suas rotinas interrompidas ${ }^{40}$.

\title{
CONSIDERAÇÓES FINAIS
}

Apresentar a experiência de trabalho do Projeto Migrantes Egressas (PME) é uma proposta de reflexão sobre um trabalho em formação, assim como de socialização e discussão

\footnotetext{
39 INSTITUTO TERRA, TRABALHO E CIDADANIA. De estrangeiras a migrantes: os 15 anos de luta do Projeto Estrangeiras. São Paulo: 2016.

$40 \quad$ Um caso emblemático que acompanhamos diz respeito a uma mulher que, em situaçáo de violência doméstica, acionou a Delegacia de Defesa da Mulher para proceder à denúncia de seu companheiro e acabou presa quando foi identificado que havia mandado de prisão em seu nome. Neste caso, além de não haver acolhimento à sua situação de violência doméstica, houve, ainda, a ampliação da violência para o âmbito institucional, já que ela foi também presa.
} 
coletiva de questôes atinentes às intersecçôes entre os temas de gênero, justiça criminal, migraçóes e políticas públicas, as quais são observadas cotidianamente na atuação do ITTC.

A observação dos dados produzidos no PME permite verificar e buscar incidir nos principais gargalos das políticas públicas no que diz respeito à migração, à atenção às pessoas com antecedentes penais, à atenção às mulheres e, sobretudo, como o cruzamento de todos esses fatores é identificado, considerado e tratado (ou não) por elas.

O PME construiu e consolidou uma metodologia de atendimento a mulheres migrantes com antecedentes penais que só foi possível pela dinamicidade entre o atendimento direto e as trocas com mulheres migrantes em conflito com a lei, o monitoramento das políticas públicas e o aprendizado permanente entre aquilo que a lei define como direito e o que é vivenciado pelas pessoas em seus cotidianos, principalmente em relação às violaçóes enfrentadas pelas migrantes com antecedentes penais na cidade de São Paulo. Neste sentido, ao expormos os dados de atendimento e uma breve descrição do trabalho realizado pelo PME e pelo ITTC como um todo, objetivamos dialogar, a fim de compartilhar esta experiência de trabalho em diferentes espaços e instituiçóes, de modo a ampliar o conhecimento sobre mulheres migrantes em conflito com a lei e de suas necessidades, principalmente para um olhar que vá além do estado de São Paulo.

Uma das principais reflexóes a respeito dessa experiência de trabalho do ITTC, por um lado, é o reconhecimento da extrema relevância em promover medidas para o desencarceramento de mulheres migrantes. Assim, nos últimos anos, a crescente garantia pelo Poder Judiciário de seu acesso às alternativas ao encarceramento e aos direitos durante a execução penal significa que as mulheres têm passado menos tempo em situação de prisão, o que inegavelmente é uma conquista. Mas, por outro lado, é igualmente necessário compreender que a saída da prisão não significa necessariamente uma ruptura com as estruturas prisionais e o acesso pleno à "liberdade".

Acumulam-se às ramificaçóes da justiça criminal os desafios atinentes à migração como um todo na cidade de São Paulo, assim como os marcadores sociais de gênero, nacionalidade e raça, de forma que, levando todos esses fatores em consideração, é preciso refletir sobre o acesso a direitos pelas mulheres migrantes egressas, especialmente de seu direito à cidade e acesso aos serviços públicos básicos, tendo em vista questóes mais amplas relativas à desigualdade social, à criminalização da migração e de condutas relacionadas a drogas. Questiona-se, deste modo, o aprisionamento como uma forma de controle migratório e de acirramento de desigualdades neste contexto de deslocamentos transnacionais.

Por fim, a atuação do PME é no sentido de compreender as dinâmicas destes processos e identificar os desafios e violaçóes que agravam ainda mais as desigualdades para que se possa propor estratégias eficazes para mitigá-las e combatê-las. Considera-se que a experiência prática e o protagonismo das mulheres acompanhadas durante a construçáo do projeto como fatores imprescindíveis para a promoção de transformaçóes significativas e busca pela garantia de direitos. 


\section{REFERÊNCIAS}

BRASIL. Ministério da Justiça. Departamento Penitenciário Nacional: Infopen, junho de 2017.

Mulheres. Brasília: 2018. Disponível em: <http://depen.gov.br/DEPEN/depen/sisdepen/ infopen-ulheres/infopenmulheres_arte>. Acesso em: 19 set 2018.

Lei no 13.445 de 2017 (Lei de Migraçôes). Disponível em: <http://www.planalto.gov.br/ccivil_03/_Ato2015-2018/2017/Lei/L13445.htm>. Acesso em 20 set. 2018.

Lei no 6.815 (Estatuto do Estrangeiro), de 19 de agosto de 1980. Disponível em: <http://www.planalto.gov.br/ccivil_03/leis/L6815.htm>. Acesso em: 01 nov. 2018.

. Lei no 9.474 (Estatuto dos Refugiados de 1951), de 22 de julho de 1997. Disponível em: <http://www.planalto.gov.br/ccivil_03/leis/19474.htm>. Acesso em 08 jul. 2019.

. Lei no 11.343 (Lei de Drogas), de 23 de agosto de 2006. Disponível em: <https://www.planalto.gov.br/ccivil_03/_ato2004-2006/2006/lei/l11343.htm>. Acesso em: 04 nov. 2018.

. Decreto no 9.199, de 20 de novembro de 2017. Disponível em: <http://www. planalto.gov.br/ccivil_03/_ato2015-2018/2017/Decreto/D9199.htm>. Acesso em: 08 jul. 2019.

Portaria Interministerial no 3, de 27 de fevereiro de 2018. Disponível em: <https://sistemas.mre.gov.br/kitweb/datafiles/Copenhague/en-us/file/Portaria\%20032018\%20vitem\%20xi\%20reuniao\%20familiar.pdf>. Acesso em 08 jul. 2019.

BUMACHAR, B. Nem dentro, nem fora: a experiência prisional de estrangeiras em São Paulo. 2016. 1 recurso online (380 p.). Tese (doutorado) - Universidade Estadual de Campinas, Instituto de Filosofia e Ciências Humanas, Campinas, SP.

CAROSIO, Alba. Feminismo Latinoamericano: Imperativo ético para la emancipación. In:Gênero y Globalización p. 229-252, 2009. Disponível em: <http://biblioteca.clacso. edu.ar/clacso/gt/20140611041611/11 caro.pdf>. Acesso em: 08 jul. de 2019.

CUNHA, Isabela Rocha Tsuji. Gênero, migração e criminalizaçáo: fronteiras e deslocamentos nas trajetórias de mulheres migrantes em conflito com a lei em São Paulo. São Paulo, 2018. 173 f. Dissertação (Mestrado em Direito) - Faculdade de Direito, Universidade de São Paulo, São Paulo, 2018.

GIACOMELLO, Corina. Género, drogas y prisión: Experiencias de mujeres privadas de su liberdad en Mexico. Tirant lo Blanch, Mexico D.F., 2013.

Mujeres, delitos de drogas y sistemas penitenciarios en America Latina. In: IDPC. Londres, 2013. 
INSTITUTO TERRA, TRABALHO E CIDADANIA. De estrangeiras a migrantes: os 15 anos de luta do Projeto Estrangeiras. São Paulo: 2016.

Defensoria Pública de SP, DPU e ITTC fazem mutiráo de atendimento

a presas estrangeiras na capital. Disponível em: <http://ittc.org.br/defensoria-publica-de-sp-dpu-e-ittc-fazem-mutirao-de-atendimento-a-presas-estrangeiras-na-capital/>; <http:/7ittc.org.br/8903/>. Acesso em 08 jul. 2019.

Projeto Migrantes Egressas (PME). Sobre o início do Projeto Migrantes Egressas apoiado pelo Fundo de Direitos Humanos dos Países Baixos. Disponível em: <http://ittc.org.br/ittc-apresenta-seu-novo-projeto-egressas/>. Acesso em: 08 jul. 2019.

10 Recomendaçóes para atuação junto a mulheres migrantes em conflito com a lei. São Paulo: 2019.

MORAES, A. L. Z. Crimigração: A relação entre política migratória e política criminal no Brasil. Porto Alegre: 2016.

Assistência transdisciplinar aos presos estrangeiros: uma abordagem prática com base na experiência da Defensoria Pública da União em São Paulo. In: Revista Brasileira de Ciências Criminais. N. 101. Mar. 2013. São Paulo: Revista dos Tribunais, 2013.

OLIVEIRA, Nathália; SESTOKAS, Lucia. A política de drogas é uma questão de mulheres. In: Revista Sur, v. 15, n. 27, p. 153-166, 2018. São Paulo.

PADOVANI, Natália Corazza. "Perpétuas espirais": falas do poder e do prazer sexual em trinta anos (1977-2009) na história da Penitenciária Feminina da Capital. Dissertação de Mestrado, Instituto de Filosofia e Ciências Humanas, Universidade Estadual de Campinas, 2010.

. Sobre casos e casamentos: Afetos e "amores" através de penitenciárias femininas em São Paulo e Barcelona (Doutorado em Antropologia Social). Universidade Estadual de Campinas, 2015.

RIVITTI, Nara. Criminalización de mujeres extranjeras em Brasil. Master en criminología y sociología jurídico penal - Universidad de Barcelona, 2014.

SÃO PAULO. Lei Municipal no 16.478 de 8 de julho de 2016. Disponível em: <https:// www.prefeitura.sp.gov.br/cidade/secretarias/upload/direitos_humanos/LEI\%2016478. pdf>. Acesso em 08 jul. 2019.

Projeto de Lei Municipal no 00537/2017. Disponível em: <http://documentacao.camara.sp.gov.br/iah/fulltext/projeto/PL0537-2017.pdf>. Acesso em 08 jul. 2019. 